\title{
The Disappearance of Change
}

\section{Towards a Process Account of Persistence}

\author{
Anne Sophie Meincke \\ Forthcoming in: International Journal of Philosophical Studies
}

\begin{abstract}
This paper aims to motivate a new beginning in metaphysical thinking about persistence by drawing attention to the disappearance of change in current accounts of persistence. I defend the claim that the debate is stuck in a dilemma which results from neglecting the constructive role of change for persistence. Neither of the two main competing views, perdurantism and endurantism, captures the idea of persistence as an identity through time. I identify the fundamental ontological reasons for this, namely the shared commitment to what I call 'thing ontology': an ontology that gives the ontological priority to static things. I conclude by briefly indicating how switching to a process ontological framework that takes process and change to be ontologically primary may allow for overcoming the dilemma of persistence.
\end{abstract}

\section{Key words}

persistence; change; identity; temporary intrinsics; endurance; perdurance; substance ontology; process ontology

\section{Introduction}

The formulation of the problem of persistence which shaped the debate in analytic metaphysics up until now was given by David Lewis: how is it possible that things change their intrinsic properties? For instance, how is it possible that this hyacinth in the park was little and green a few days ago and is big and blooming today? Such changes apparently involve one and the same thing having different properties at different times. But this seems impossible given that 'being the same', according to Leibniz's Law, implies having the same intrinsic properties (Lewis 1986: 203f.). 
In this paper I argue that so far theories of persistence have aimed to solve Lewis' puzzle by silently getting rid of change, and that this is why they fail. Because change is generally assumed to be a false-maker of statements of identity, the common strategy is to explain identity at the expense of change. Change - whether in perdurantist or endurantist frameworks - disappears. However, as a result, persistence disappears too. We cannot have persistence without change. Instead, only if we think of change as both a possible falsemaker and a possible truth-maker of statements of identity, namely identity over time, are we in a position to give a plausible account of persistence.

I shall proceed as follows. Section 2 and 3 are devoted to diagnosing the disappearance of change, and the collapse of the concept of persistence which follows it, in both perdurantism and endurantism. This reveals the characteristic dilemma of the debate, which oscillates between trying to assemble persistence from a plurality of discrete existents on the one hand and postulating some sort of primitive identity on the other. In section 4 I shall show how this dilemma issues from an underlying shared commitment to what I call 'thing ontology': an ontology that gives the ontological priority to things, i.e., to entities for the identity of which change is not essential. I shall conclude in section 5 by briefly indicating how we may overcome the dilemma by switching to process ontology which takes processes to be ontologically primary, i.e., entities for the identity of which change is essential.

\section{The Disappearance of Change I: Perdurantism}

According to Lewis' canonical definition, something 'perdures' if it persists "by having different temporal parts, or stages, at different times, though no one part of it is wholly present at more than one time" (Lewis 1986: 202). Persisting objects are taken to be fourdimensional objects composed not only of spatial but also of temporal parts. None of these temporal parts is changing itself; instead, change is supposed to consist in different such temporal parts instantiating incompatible properties. Perdurantism thus, apart from preserving the intrinsicness of properties, delivers a theory of persistence that does justice to change in a Leibniz's Law-compliant way. Or so it seems. For is there really any change under perdurantism?

So far, doubts about this have mostly targeted perdurantism's common commitment to eternalism and four-dimensionalism, i.e., to the view that all times are equally real and that 
time is strictly analogous to space. Following a line of argument first presented by McTaggart (1927: ch. 33), perdurantism has been accused of not admitting of changing facts and of collapsing temporal change into spatial variation. ${ }^{1}$ The perdurantists' common reaction to this so-called no-change objection is to insist that what the objector denies being change just is change - full stop. In this manner, e.g., Sider (2001: 214) recommends meeting McTaggart's objections simply "head-on" by claiming that "[c]hange is analogous to spatial variation" and "does occur in virtue of unchanging facts about temporal parts" (italics in the original). Similarly Haslanger (2003: 333) grants (standard) perdurantism that its commitment to eternalism "does not undermine the claim that change has occurred, for, the perdurantist maintains, change occurs when an object's temporal parts have incompatible properties". She goes on to argue that while, "[a]dmittedly, change may not appear familiar to us when considered from a timeless perspective", nevertheless, "the 'no change' objection, by itself, does not force us to abandon the eternalist accounts of persistence" because there need not be a full match between "the phenomenology of change" and "the ontology underlying the phenomenology" (ibid.).

Can change really be separated from time (and vice versa)? I don't think so, and, hence, if eternalism, as Haslanger surmises (and as the term 'eternalism' suggests), indeed comes down to taking a "timeless perspective" on reality, then it seems to me that the chances of finding any change in that reality cannot be anything but zero. In eternity, there is no time and no change either. However, the claim which I want to defend here is that, when worrying about the reality of change under perdurantism, we actually should focus not on time but on ontology. According to what I would like to call the 'argument from ontological atomism', the very act of splitting the persisting entity up into a bundle of unchanging components causes the demise of change - and thereby also eliminates persistence; something that has not yet attracted the attention it deserves.

Consider Paula who is first in love with Ernest, then falls in love with Peter and later with whomever. The perdurantist re-describes this situation (simply put) by saying that Paula actually consists of three temporal parts one of which is in love with Ernest, another one of

\footnotetext{
${ }^{1}$ See Sider (2001: 212f.) for the distinction of these two different aspects of McTaggart's critique. For a critical discussion of perdurantism along the lines of the second aspect - the 'argument from spatial analogy' as Sider calls it - see Oderberg (2004) and Geach (1972: 304f.). Haslanger (2003: 332f.) presents a version of the first aspect. Simons (2000a: 134-137), addresses both aspects.
} 
which is in love with Peter and another one of which with whomever, so as to avoid the feared contradiction that one and the same thing has different properties. It is not true that there is one single thing - Paula - finding itself caught up in changing (and supposedly incompatible) romances. All there is are different things with different properties, and, as Lewis puts it, "[t]here is no problem at all about how different things can differ in their intrinsic properties" (Lewis 1986: 204). However, as already Simons (2000b: 65) has rightly observed, this in effect means there is no change. Different things are different things and so there is nothing that changes over time. My point is that, as a consequence, perdurantism fails to account for persistence too. For how could there be persistence without there being something that persists through time?

Note that this difficulty occurs for all versions of perdurantism under any theory of time. Brogaard (2000) has suggested combining four-dimensional perdurantism (also called 'worm-theory') with presentism. An object then would persist by having different temporal parts each of which exists only at the present time. This seems to help with the McTaggartian concern that there cannot be change without the possibility of changing facts, by reinstalling the passage of time. However, apart from the difficulty to understand how something can be composed of non-existing parts (Benovsky 2007), it still does not give us the sort of change needed for persistence: there is nothing that changes over time, and nothing that persists through time either; instead, one unchanging thing is replaced with another unchanging thing. ${ }^{2}$

Similarly, combining perdurantism with the growing block theory of time (e.g., Tooley 1997), we could hold that an object persists by having different temporal parts which add up in time. However, we would still end up at every instant with a different object. On the 'worm' view, entities persist as the mereological sums of their temporal parts. Given that mereological sums are individuated by their elements (Lewis 1991: 80), every occurrence of a new temporal part, i.e., every occurrence of a new property causes the mereological sum

\footnotetext{
2 Benovsky (2007) convincingly argues, too, that presentist perdurantism fails to meet the 'no-change objection'. From the observation that "it is not presentism (the rejection of eternalism) that can save the case of four-dimensionalism" (83) with respect to the "intrinsic change of an entity" (82), he also rightly concludes that perdurantism itself is the problem, not the eternalist theory of time it is usually combined with. However, he neither notices that this directly affects the credibility of perdurantism as a theory of persistence nor does he investigate the ontological issues lying at the root of this problem.
} 
which had been there before to be replaced with a new (bigger) one. ${ }^{3}$ Finally, we could adopt the stage view that does without the idea of composition, assuming that things are their stages occurring at certain times, and that things persist by having stages at other times as temporal counterparts (Sider 2001). However, again, whether we combine this view with eternalism, growing block or presentism, the result will be different things with different properties, either all being equally real, or increasing in number or replacing one another in time. $^{4}$

The argument from ontological atomism draws attention to the fact that there is something substantially wrong with perdurantism, indicated by the fact that with whatever theory of time we combine it, we end up explaining away what we wanted to explain: how entities persist through time while changing in time. I thus want to contest the assumption commonly made by critics, that perdurantism is actually fine as an account of persistence, its deficiency only being that it eliminates change (which is commonly associated with perdurantism's eternalist stance on time). My view is that perdurantism doesn't account for persistence at all. More precisely, I take it that perdurantism fails to account for persistence just to the extent that it fails to account for change on ontological grounds: by splitting entities up in unchanging parts.

Interestingly, Haslanger touches on the ontological dimension of the issue when distinguishing from the standard 'no change' objection a second version which she calls the 'no alteration' objection. On this version, she says,

stages are thought to come into and go out of existence instantaneously in succession. So it is granted that there is change (indeed, almost nothing but), but because there is nothing that gains or loses one of its properties, there is no genuine alteration. The stages come and go, but do not alter; the persisting thing has different parts with different properties, but it too does

\footnotetext{
${ }^{3}$ As far as I see, no one has yet defended 'growing block perdurantism'.

${ }^{4}$ Benovsky (2007) discusses the stage view as a potential alternative to presentist perdurantism but dismisses it on the grounds of the ultimate unintelligibility of the postulated counterpart relation. Sider, who defends the stage view in combination with eternalism, speculates about the hypothetical position of a presentist stage view (2001: chapter 2), and Hansen (2010) attempts to work out such a view. I did not come across a defence of a 'growing block stage view'.
} 
not alter. So persistence (as perdurance) through time may be achieved, but genuine alteration is denied (Haslanger 2003: 332f.; italics in the original). ${ }^{5}$

Alteration - or 'qualitative change' - is usually distinguished from 'substantial change' in the sense of 'becoming' and 'passing away'. Accordingly we can understand the objection, as put by Haslanger, as being the worry that while we seem to be able to accommodate the latter sort of change under perdurantism - by postulating an instantaneous becoming and passing away of stages or temporal parts along the lines of what we could call the 'replacement model' of change, we yet lack the former sort of change insofar as we lack a proper subject of change - something "that gains or loses its properties".

Now we might expect that if there are doubts as to the existence of a proper subject of change (in the sense of 'alteration'), then there should be doubts as to the existence of a proper subject of persistence too. In other words, any reasons to question a theory's ability to account for alteration thereby should put this theory's status of being a theory of persistence at stake. Astonishingly, this is mostly not the case in the debate; and we see why when looking at how Haslanger refutes the 'no alteration' objection: "alteration", she says, "can be understood simply as variation in the intrinsic qualities of a thing" (Haslanger 2003: 333), adding: "According to the perdurantist, having a straight-stage and a bent-stage is our best account of such variation: bentness and straightness are incompatible properties of the stages that are parts of the persisting thing" (ibid.).

This is the standard story of persistence as perdurance which can only appear to be an account of persistence to the extent that it works with a linguistic trick: it talks of something like a 'persisting thing' while actually, i.e., ontologically, denying that there is such a thing, assuming instead that there are many things, things which misleadingly are called 'parts' (namely 'temporal parts'). ${ }^{6}$ The normal semantics of the term 'part' implies there being

\footnotetext{
${ }^{5}$ I have to admit that I am puzzled by Haslanger's assumption that both versions of the 'no change' objections she presents “assume an eternalist version of perdurantism" (Haslanger 2003: 332). I don't see how under eternalism stages can be "thought to come into and go out of existence instantaneously in succession" if this is meant to be a statement about ontology rather than about the - allegedly illusive - phenomenology of change. ${ }^{6}$ This trick includes the invention of the rather obscure concept of 'having properties derivatively': “To be sure, my shapes belong in the first instance to my stages, and in a derivative, relational way to the whole of me" (Lewis 1988:66).
} 
some 'whole' the part is part of. ${ }^{7}$ However, there are no wholes in a proper sense in perdurantism: the four-dimensional entities which are rhetorically addressed as 'persisting things' are, as already mentioned, supposed to be mereological sums, and a mereological sum, according to Lewis, "is nothing over and above its parts, so to describe it you only need to describe the parts" (Lewis 1991: 80). I don't see why anyone not driven by the particular motivations of perdurantism would want to accept mereological sums as proper subjects of statements of persistence, especially not under the conditions of unrestricted composition which Lewis famously defended (Lewis 1986: 211).

The common interpretation (shared also by Haslanger, see 2003: 318 and 331f.) therefore is that perdurantism in fact has given up on what Haslanger calls the 'proper subject condition', according to which "[t]he object undergoing the change is itself the proper subject of the properties involved in the change" (Haslanger 2003: 317). The crucial question then is this: can there be persistence without a proper subject of persistence? In earlier work, Haslanger has explicitly denied this, arguing that replacing the proper subjects of statements of alteration with "successions of momentary objects which are related in special ways" (Haslanger 1989b: 10) amounts to denying that "[t]here are some objects which persist through alteration" (Haslanger 1989b: 4): "So the tree, the candle, the leaf, don't alter, i.e., don't persist through their changes, after all" (Haslanger 1989b: 10). ${ }^{8}$ I think this is exactly right.

The conclusion to be drawn from this is that perdurantism fails to account for persistence, if we assume, as I think we usually do, that for something to persist means that it continuously exists as the same through time. ${ }^{9}$ If perdurantism gives us any change at all, to the extent

\footnotetext{
${ }^{7}$ Lowe (1988: 68ff.) accordingly surmises that the identity of the entity any given temporal parts are supposed to be part of is actually circularly presupposed.

${ }^{8}$ In her 2003 article, despite calling perdurantism's rejection of the proper subject condition "a disadvantage", leading to a rather "strange claim" (331), Haslanger appears to be friendlier to perdurantism. She still acknowledges the task to account for alteration as being at the heart of the debate on persistence, but now seems to believe that one could have persistence without alteration as apparent from the above quoted passage. I take it to be a particular strength of her earlier view that it recognises the interconnectedness of persistence and 'alteration'.

9 This understanding of persistence is stronger and more distinctive compared to the supposedly 'neutral' definition of persistence given by Lewis according to which something persists if it "exists at various times" (Lewis 1986: 202).
} 
that it fragments the supposedly persisting entity into a plurality of unchanging discrete entities, it still does not give us that sort of change that we need to make sense of persistence. I am thereby not saying that 'alteration' is sufficient to make sense of persistence; ${ }^{10}$ however, I do want to insist that replacement of instantaneous static entities certainly is not the model that helps us with this task.

Allocating the troublesome incompatible properties involved in qualitative change to different (themselves unchanging) entities rather than to one and the same entity is a smart and elegant trick to avoid violation of Leibniz's Law. However, we had been asking a question exactly about how one and the same entity can differ in its intrinsic properties over time. It thus seems that Lewis either changes the subject leaving us with no answer at all or, as Haslanger (1989b: 11) already suspects, comes up with an answer that rather problematically redefines what our question was about, thus obscuring the fact that the answer to that question actually is simply No: according to perdurantism, no thing can ever differ in its intrinsic properties over time; nothing changes. And nothing persists - continues existing as the same through time - either.

\section{The Disappearance of Change II: Endurantism}

Proponents of endurantism often claim that they deliver the only coherent account of change at all, namely by virtue of the very assumption that things persist by enduring, i.e., according to Lewis's definition, "by being wholly present at more than one time" (Lewis 1986: 202). On endurantism, there is, they argue, something that changes, namely the enduring three-dimensional thing which, as the proper subject of the various properties attributed to it over time, is numerically the same at any times these attributions are made. And they add that this could not be otherwise: Saying, e.g., 'Tom has become lazy since his promotion' does not make sense if not implying that it is the very same person who had been diligent in the past and is lazy now. Numerical identity is presupposed in any attributions of change for logical reasons. ${ }^{11}$

\footnotetext{
${ }^{10}$ For reasons which become clear in the remainder of this paper I think this is exactly not the case. See also footnote 22.

${ }^{11}$ Chisholm (1969) distinguishes accordingly between the 'strict and philosophical' sense of numerical identity and a 'loose and popular' sense of 'identity' that covers qualitative change and presupposes 'strict' identity. For the relevance of this argument in the context of the debate on personal identity see Meincke (2015).
} 
What we could call the 'argument from logical presupposition' translates into an ontological claim which, as it seems, amounts to the antithesis of the ontological atomism observed and criticised with respect to perdurantism: according to endurantism, instead of there being many different things instantiating different properties at different times, there is exactly one thing instantiating different properties at different times. This appears to be in perfect alignment with the concept of change as alteration: the enduring thing changes its properties by functioning as a substratum of such change.

Yet, the claim which I want to defend in this section is that endurantism no less than perdurantism eliminates change and that in doing so it fails as an account of persistence too. The 'substratum model of change' (which appears in a variety of versions in endurantism) is no more able to give us the sort of change required for persistence through time than is the 'standard story of perdurantism' or the (cognate) 'replacement model of change'.

Lewis (1986: 204) famously dismisses endurantism because it sacrifices the intrinsicness of properties and thus, he claims, fails to offer a solution to the problem of temporary intrinsics. This criticism refers to the relationalist 'standard story' of endurantism which reconceptualises intrinsic properties, such as the hyacinth's being little and green and the hyacinth's being big and blooming, as disguised relations to times: the hyacinth is little-andgreen-at- $t_{1}$ and big-and-blooming-at- $t_{2}$. Lewis complains that this account collapses intrinsic change into relational change, such as my changing from being-taller-than-my-son to beingshorter-than-my-son as time passes by. While re-describing the latter as triadic relations that include times seems fine to Lewis, he insists that we would fail to capture the phenomenon of the hyacinth changing from being little and green to being big and blooming if treating it in the same way as incorporating different relations to different times.

Haslanger (2003: 329) defines intrinsic properties as "those properties [the object] has by virtue of itself alone, and not by virtue of its relations to other things" and agrees with Lewis that temporary intrinsics matter because

we do want to accommodate the phenomenon of intrinsic change, more specifically, to have an understanding of what it is to be a subject of properties that makes intrinsic change possible. Objects have some intrinsic properties: some of their properties are due just to how they are. But, surprisingly perhaps, objects sometimes change in these very respects - in shape, in their internal workings, in how they themselves are. How can we capture this? (Haslanger 2003: 330; italics in the original) 
Haslanger's suggestion is that the relational character of time-indexed properties does not prevent these from being intrinsic to the object that has them. ${ }^{12}$ But she hastens to concede that we equally also could do without intrinsicness because

there is nothing irrational in denying the phenomenon of intrinsic change and maintaining that all alteration is relational. An account that allows us to capture intrinsic change would be attractive, but we've seen no argument that giving up intrinsic change would be a disaster (ibid.). ${ }^{13}$

This move is surprising, not only because it is in tension with Haslanger's emphasis on our interest in intrinsic change, but also because it seems to entail the belief that there can be alteration without genuine - 'intrinsic' - change. Can there really?

I think not. My view is that there is actually no change at all in relationalist endurantism. Just think of what relationalism is meant to do: it is meant to make endurantism comply with Leibniz's Law by removing the incompatibility of the persisting thing's properties. If those properties cease to be incompatible with one another because time enters into them as a defining aspect, then it becomes possible to attribute all of these properties (as far as we know them) to the persisting thing at all times at which it exists so that Leibniz's Law is fulfilled: the persisting thing has the exactly same properties at any time and hence is numerically self-identical at any time. However, this means, as Johanna Seibt (1997: 155f.) already noticed, that the persisting entity actually does not change. It is not true that the persisting thing has, at some time, properties (whether intrinsic or relational) ${ }^{14}$ that it does not have at other times, as the idea of change would require.

Reconsider Paula who is first in love with Ernest, then falls in love with Peter and later with whomever. According to the relationist endurantist, Paula is not composed of different temporal parts, each instantiating a different love affair. Instead, Paula has the properties 'being-in-love-with-Ernest-at- $t_{1}$ ', 'being-in-love-with-Peter-at- $t_{2}$ ' and 'being-in-love-with whomever-at- $t_{3}{ }^{\prime}$, and she has all of these properties at all times $t_{1}, t_{2}$ and $t_{3}$. Paula thus is

\footnotetext{
12 "Relations to times are exactly the sort of relations that may plausibly count as intrinsic" (Haslanger 2003: 330). Adverbialism is another strategy to re-establish the intrinsicness of temporary properties (Johnston 1987, Lowe 1988, van Inwagen 1990, Haslanger 1989a and 2003: 341ff.), but it remains controversial whether it is a successful strategy (Merricks 1994, Hinchcliff 1996, Lewis 1988 and 2002, Sider 2001, Bottani 2016).

${ }^{13}$ See also Wasserman (2003) for a defence of relationist endurantism along these lines.

${ }^{14}$ Leibniz's Law includes both.
} 
'wholly present' at all times; there is no part - and no property - of her missing at any time. Leibniz's Law is fulfilled; Paula is numerically the same at any time. However, she doesn't change. She is just the same at any time of her existence; whether we meet her at $t_{1}, t_{2}$ or $t_{3}$, Paula is always in (time-indexed) love with (at least) three different people. This clearly does not capture what it was meant to explain: that Paula first loves Ernest, then loves Peter, and then someone else.

Note again that this is not a problem of the theory of time presupposed by relationalist endurantism. The version targeted by Lewis's criticism is eternalist relationalist endurantism. As eternalism has it, all times at which Paula exists are equally real, and the same then holds for Paula's existence. Paula at $t_{1}$ is no less real than Paula at $t_{2}$, nor is Paula at $t_{3}$, even if we refer to her from the perspective of $t_{2}$. To this we add the implication of relationalist endurantism that at all of these times Paula has the same properties. The result is that, just as would be the case if Paula were a four-dimensional space-time-worm, Paula's existence is entirely static, in the double sense of the absence of both qualitative and substantial change. In other words, eternalism completes the static picture drawn by relationalist endurantism, but it is not to be held responsible in the first place for relationalist endurantism's failure to account for intrinsic change.

We might wonder whether things would improve if we were to switch to presentism instead. We would then have to assume that Paula exists only in the present, again 'as a whole', i.e., including all of her time-indexed properties. Accordingly, we would have to say, at $\mathrm{t}_{1}$, that it now is true of Paula that she 'is-in-love-with-Ernest-at- $\mathrm{t}_{1}$ ' and 'is-in-love-withPeter-at- $\mathrm{t}_{2}$ ' and 'is-in-love-with whomever-at- $\mathrm{t}_{3}$ '. The same thing, however, we would have to say at $t_{2}$ and equally at $t_{3}$. So even if there were ways around the fundamental worry that things that exist only in the present can change over time as little as they can persist through time (Lewis 1986: 204), this would not help establish change since whenever Paula exists (i.e., at whatever time that is the present), she has the very same properties anyway. ${ }^{15}$

\footnotetext{
${ }^{15}$ Endurantism, if presuming presentism rather than eternalism, usually would partner up with a 'serious tenser' approach rather than with relationalism, and one might wonder, in general, whether serious tensing might help with re-installing intrinsic change. I don't see how this could be done within the common framework of the debate without running into a violation of Leibniz's Law. On the other hand, if combined with eternalism and endurantism, serious tensing, as it were, loses its point inasmuch as we, in order to avoid
} 
Haslanger is aware of the fact that relationist endurantism has a problem not only with intrinsicness but also with change. She writes:

Paradox is avoided because there is no inconsistency in standing in the bent at relation to one time and the straight at relation to another. Yet because being straight at $t$ and being bent at $t^{\prime}$ are compatible, there is a sense too in which the incompatibility condition has been sacrificed. This is meaningful because the incompatibility condition is what seems to capture the fact that change occurs (Haslanger 2003: 328; italics in the original).

The 'incompatibility condition' requires that '[t]he properties involved in a change are incompatible" (Haslanger 2003: 316). In response, Haslanger suggests that we distinguish between relational properties and the corresponding relations, claiming that while the former are not (and must not) be incompatible with one another, the latter are incompatible with one another, thus accommodating our intuitions about intrinsic change:

Even though being bent at $t$ and being straight at $t^{\prime}$ are compatible, being bent at and being straight at are incompatible in the sense that the candle could not stand in both relations to the same time. In other words, it may be that the relations in question are incompatible, even if the relational properties, i.e. the properties of being straight at $t$ and being bent at $t^{\prime}$ [sic], are compatible. The fact of change is captured because the candle cannot stand in both the straight at and bent at relations unless it persists through a change, represented by its different relations to different times (Haslanger 2003: 329; italics in the original).

I have doubts as to whether this argument really goes through. Apart from the fact that the incompatibility condition, which so far is defined for properties, not for relations, would need to be reformulated so as to make Haslanger's proposal comply with it, there is the difficulty to make sense of the postulated relations of the type 'being bent at' and 'being straight at'. What are these relations? Are there any such relations at all? Answering the latter question in the affirmative seems to imply attributing some universal status to them. 'Being bent at' and 'being straight at' would be types, instantiated by, e.g., 'being bent at $t^{\prime}$ and 'being straight at $t^{\prime}$ ' as tokens. But the possibility of properties as types under relationalism can be (and has been) questioned. Thus Benovsky (2008: 188) convincingly 
argues that "time-indexed properties are tropes" (italics in the original). ${ }^{16}$ If so, however, there is no way to construe any incompatibility between the relational properties possessed by persisting things according to the relationalist, which is to say that relations such as "being bent at' and 'being straight at' do not exist independently of particular time-indexed and in that sense relational properties. ${ }^{17}$

If Paula doesn't change under endurantism, does she persist through time at least? This question might seem surprising. One would surmise we had answered it already by pointing out that Paula is numerically the same at any time she exists because she has the same (time-indexed) properties at any times she exists. However, I think the fact that we can refer to Paula as numerically the same at different times does not actually prove that Paula persists through time.

According to relationalist endurantism, as explained, Paula has all her (time-indexed) properties at all times at which she exists. That means Paula has, e.g., at $\mathrm{t}_{1}$ the property 'being-in-love-with-Ernest-at- $t_{1}$ ', but also the property 'being-in-love-with-Peter-at- $t_{2}$ '. This is hard to understand. What does it mean to say I now have the property of being in love with someone later? Invoking a distinction between '(merely) instantiated' (or 'exemplified') properties on the one hand and 'manifested' properties on the other would cause conflict with Leibniz's Law again and, hence, cannot solve the issue (Seibt 1997: 156). It follows that there is nothing that makes Paula's 'being-in-love-with-Peter-at- $t_{2}$ ' true at $t_{2}$; it was true at $t_{1}$ already all the same (and will be at $\mathrm{t}_{3}$ and any other times). It is timelessly true. ${ }^{18}$

\footnotetext{
16 "In the indexicalist's world there is no room for a single property to be multiply instantiated, since any property is time-bound and cannot be instantiated at different times, and so there simply is no room for universals (multiply instantiable properties)" (ibid.). (Benovsky uses the term 'indexicalism' for what Haslanger calls 'relationalism'.)

17 Note that this consequence cannot be escaped by drawing a sharp line between relations and relational properties. There is no such sharp line. Standing in the 'bent-at' relation to $t_{1}$ just as naturally translates into the relational property 'being-bent-at- $\mathrm{t}_{1}$ ' as standing in the relation of 'being-taller-than' to my son translates into the relational property 'being-taller-than-my-son'.

${ }^{18}$ Bearing in mind what I said earlier about presentist relationalist endurantism, note that this applies on whatever theory of time we combine relationist endurantism with. Surely, eternalist relationist endurantists will not be disturbed by the lack of temporal truth-makers; but they should feel disturbed by the fact that this in effect undermines their claim that the enduring entity can be truly said to persist through time.
} 
Saying that something has all its properties at any times corresponds with the way we talk about abstract entities, not about concrete objects that exist in time. A number, for instance, has all its properties at any times, but that is exactly because a number does not exist in time; or at least it does not have the sort of temporal existence that candles, hyacinths or people have. The difficulty to understand the standard story of endurantism - that properties are relations to times and that, because time-indexed properties are not incompatible with one another, they can be attributed to the enduring things at any time so that numerical identity is maintained - thus reveals that time, in the sense of the time in which time-indexed properties are taken to be instantiated, is fictitious. The enduring thing possesses its properties just as timelessly as does the perduring four-dimensional aggregate of temporal 'parts'. It does not have its properties in time, from which we can infer that it is not stricto sensu in time itself. ${ }^{19}$

The point is that what is not in time cannot persist through time. Hence, the common idea that enduring things move through time is mistaken. It is an illusion deriving from the fact that we can refer at multiple times to, say, Paula as numerically the same. However, according to endurantism, at any instants in time at which we refer to her, Paula is actually numerically identical as a brute, timeless matter of fact. Numerical identity as such, as it turns out, doesn't give us persistence through time if we thereby mean that something continuously exists through time.

19 Benovsky (2008) makes a similar observation when trying to figure out the most appropriate visual representation of the endurance model of persistence. Assuming this representation should include a bundle of time-indexed properties plus some unifying device (which could be either a compresence relation or a substratum), he explains that there is no need to repeat this representation for every point in time (Benovsky's example of Cyrano, who changes from having a big nose to having a small nose, involves three times): "First, why draw three times the same thing? These three bundles of properties are not three bundles located at different temporal locations, rather they are one and the same. Drawing the same thing three times is here totally redundant and unhelpful. Second, the time-axis is also redundant - we do not need it in order to know what is happening to Cyrano at different times, since all temporal specifications are already included in the properties of which Cyrano is a bundle" (181). As Benovsky puts it, "Cyrano is simply a bundle of time-indexed properties" (ibid.) - plus (in the case of the substratum model) a substratum that bears (and thereby unites) these properties. Indeed, why should time occur twice in the picture? The only justification for locating the entity composed of time-indexed properties and a substratum on a time-axis could be the fact that we refer to this entity in time; but as the analogous example of a number shows, this by no means proves that what we refer to in time exists in, and persists through, time. 
The supposed primitiveness of the enduring entity's numerical identity is in line with the substratum model of change. A substratum is, as Benovsky (2008: 176) formulates, "a bearer of properties, which has its identity independently of the properties which it bears". The idea is that any change of properties (in the sense of properties replacing each other in time) must occur upon an underlying subject which itself does not change. However, as Peter Geach (1979: 46f.) already astutely noticed, this view is astonishingly incoherent: it comes down to the claim "that a thing undergoes no change precisely because it does undergo change". And what is worse, there is, as we have seen, in fact not any change if we combine the substratum model of change with relationalism according to the standard story of endurantism. It remains a mystery to me why Haslanger thinks there could be alteration without intrinsic change, the latter of which we indeed - contrary to what endurantists claim - do not get in the endurantist picture. Endurantism is as far from delivering the only coherent account of change as anything could be, and just to the extent that it fails to accommodate change it also fails to account for persistence.

\section{Thing Ontology and the Dilemma of Persistence}

I have argued that neither perdurantism nor endurantism succeed in making sense of the fact that things stay the same while changing. The reason for this turned out to be that they cannot account for change in the first place. Perdurantism fragments persisting entities into bundles of tiny and discrete things that themselves do not change. Nothing changes here, and nothing persists over time, because there is nothing that could change and persist over time. Endurantism, on the other hand, does give us a subject - the numerically self-identical enduring thing, as it seems; however, this enduring thing neither changes nor persists over time. It is numerically self-identical in a timeless way, defying any investigations into how this identity comes about.

In terms of ontology we can trace back this dilemma to the antagonism between Humeanism and substance ontology. Perdurantism presupposes a bundle theory of things, according to which things are bundles of smaller things (events, matters of fact, universals, tropes), tied together by some sort of binding relation. Given this view, it is clear from the start that things cannot be self-identical through time, identity rather being restricted to the identity of the unchanging individual elements of the bundle. But there is more to the story. Humean ontologies are ontologies that generally take unchanging discrete entities to be the 
basic constituents of reality. ${ }^{20}$ Change reduces to the contingent distribution of intrinsic properties of point-sized things located in space-time. With these ontological commitments in place, change cannot be more than an abstraction, and the same holds true for the idea of persistence as an identity over time. Identity is the identity of things as defined by Leibniz's Law, and it would be destroyed if there were any change. Hence, change is abandoned, and we end up with the bizarre view that to persist means to be a series - an 'aggregate' - of short-lived, discrete and unchanging space-time portions.

On the other hand, endurantism operates upon some version of the idea first brought up by Aristotle, namely that things are substances. Substances are taken to be discrete particulars and as such the invariant subjects of changing properties. In other words, the concept of a substance was invented exactly to make sense of the fact that things seem to persist even though they change; however, it does so by blocking any questions as to how this is achieved. Even if we, with Aristotle, assumed that an enduring thing really changes its properties over time, given the view that enduring things are substances there would be no way to explain how this is possible without the enduring thing's numerical identity being affected by that change: this is just what substances do. ${ }^{21}$

This is, admittedly, a simplified presentation of Aristotle's view. As is well known, Aristotle distinguished between so-called essential and so-called accidental properties only the latter of which he thought can actually change over time without the substance's identity thereby being affected. ${ }^{22}$ Speaking in modern terms, accidental properties are exempted from Leibniz's Law (or Leibniz's Law is restricted to essential properties). In contrast, as we have seen, contemporary endurantism aims to comply fully with Leibniz's Law. Note, however, that the idea of a substratum (or 'bare particular') deployed by contemporary endurantism entails the same resistance against analysis (and thus an element that is in tension with the

\footnotetext{
${ }^{20}$ Lewis has explicitly defended this view under the title 'Humean supervenience', which is "the doctrine that all there is to the world is a vast mosaic of local matters of particular fact, just one little thing and then another" (Lewis 1986: ix).

21 "It seems most distinctive of substance that numerically one and the same thing is able to receive contraries" (Aristotle, Categories 4a 10ff.).

22 This is what Aristotle calls 'alteration'. Insofar as this concept entails the assumption of there being an unchanging substratum of change (in line with what I called earlier the 'argument from logical presupposition'), I find the usage of this term in the context of explanations of persistence not helpful.
} 
spirit of Leibniz's Law): the substratum is supposed to have its identity independently of its properties. Accordingly, the numerical identity of the substratum of properties appears as a brute fact to which we can refer at multiple times, thus creating the illusion of persistence, i.e., of an identity over time.

Substance ontology crucially rests upon the idea that change - if there is any - must have a non-changing basis. Whatever appears to change is believed to have an unchanging core. Change, if it exists at all, is taken to be parasitic upon stasis; it does not have an independent ontological status. It resembles the fluctuating images on a mirror surface, leaving the mirror itself the same whether it shows microbes on a Petri dish, a murder or passing clouds. And this is already the most optimistic and sympathetic description of the substance ontological attitude towards change that we can give and that, as we have seen, is not applicable to contemporary endurantism. Contemporary endurantism erases even that little bit of change its Aristotelian predecessor allowed for; to speak again metaphorically, it keeps the mirror, keeps the images, but gets rid of the fluctuation of the images.

The two apparently opposing ontologies thus turn out not to be so different after all. They are rather two versions of the same overall ontology which I call 'thing ontology'. According to this ontology, the basic constituents of reality are things, i.e., entities the identities of which can be determined independently of any change. Substance ontology postulates bigger things, called substances; Humeanism works with smaller things, called temporal parts, standardly taken to compose bigger things, called four-dimensional entities. Neither of these things needs to change in order to be what they are; even an Aristotelian substance can perfectly well sit there without doing anything. Furthermore, neither of these things can change after all as this is believed to corrupt their identity (accidentally changing Aristotelian substances ex hypothesi excluded). This shared commitment to thing ontology explains why - despite their differences - change disappears in both perdurantism and endurantism and why persistence does too. ${ }^{23}$

\footnotetext{
${ }^{23}$ Similarly, Johanna Seibt has diagnosed Western metaphysics with being under the spell of the 'myth of substance' (1997: 143). However, even though she characterises this 'myth' in terms of a set of principles not unique to what traditionally has been called 'substance ontology', I find the choice of terminology unfortunate given the continuous antagonism between Humeanism and traditional 'substance ontology'. More importantly, however, Seibt seems to accept the core feature of what I (more neutrally) call 'thing ontology': the assumed
} 


\section{Towards a Process Account of Persistence}

Within the framework of thing ontology, identity is defined so that it does not allow for change in principle. Not surprisingly then, the most effective way to solve the so-called problem of change (Wasserman 2006) is to just get rid of change - either by dissolving it into an assembly of properties of disparate things or by neutralising it as merely relational on the basis of a presumed underlying identity of one single thing. But why should we subscribe to thing ontology?

The best strategy to convince metaphysicians to leave well-trodden paths of thinking is arguably to come up with a better alternative. I believe there is indeed such a better alternative: a process account of persistence. The process account of persistence takes seriously the outcome of the analysis that it appears to be impossible to obtain a convincing explanation of persistence as an identity through time within an ontological framework that has no space for change. Could it not be that persistence requires change rather than excluding it?

A positive answer to this question seems unavoidable when it comes to living beings. Just think for a moment what a hyacinth is and how it persists through time. It is true that the hyacinth can survive certain changes; but the hyacinth would not be there at all if certain changes were not taking place that keep the hyacinth going: photosynthesis, the filtering and transport of nutrients from the soil up to the aerial parts of the plant, growing processes and so on. There is no hyacinth beyond the process of its own constitution, consisting, most fundamentally, in a constant exchange of matter and energy with the environment.

With respect to the biological domain, it is impossible to evade the insight that change is not only a false-maker but also, and foremost, a truth-maker of statements of persistence. According to process ontology this is a general truth about reality. Process ontology gives the ontological priority not to things but to processes, i.e., to entities to the identity of which change is essential. As a consequence, change re-appears, namely as the sediment of reality out of which whatever exists arises. Things, if there are any, have to be re-conceptualised as stabilised processes (Meincke 2018a, 2018b and forthcoming). The conditions of process stabilisation can be scientifically investigated, and they will be different for different kinds of 
process. However, what matters from a metaphysical point of view is that any process of whatever kind persists as long as stabilisation can be maintained.

Process ontology calls for a change of perspective: rather than asking how change is possible, we have to ask how identity is possible. This entails the insight that identity whether synchronic or diachronic - cannot be taken for granted but is rather an exceptional and hard-won feature of the world we live in. As future work, engaging with both the recent process ontological turn in the philosophy of biology (Nicholson \& Dupré 2018, Dupré 2012, Bickhard 2008) and the currently emerging debate about the metaphysical nature of processes (Galton 2017, Steward 2013 and 2015, Galton \& Mizoguchi 2009, Stout 2016 and 1997), will have to show in more detail, such a change of perspective allows for an informative account of persistence through time that does not eliminate what it was meant to explain.

\section{Acknowledgements}

This paper was funded by the European Research Council, grant agreement number 324186 (“A Process Ontology for Contemporary Biology”, grant holder: John Dupré). I am indebted to John Dupré, David Wiggins, Antony Galton and Stephen Mumford for inspiring discussions and very helpful comments on earlier drafts of this paper. Different versions of this paper were presented at the international workshop Time and Change, organised by S.P.O.T. (Society for Philosophy of Time), at the University of Bonn, Germany, in July 2016; at the Philosophy Colloquium at Trinity College, Dublin, Ireland, in February 2017; and at the Colloquium of the Metaphysics of Entanglement group at Corpus Christi College, University of Oxford, UK, in May 2017. I am grateful to the inviting institutions and to the audiences for stimulating discussions. I would also like to thank the audience of the presentation given at the final conference (Process Biology) of the research project at the Royal Institution in London, UK, in March 2018.

\section{References}

Benovsky, J. (2007) 'On Presentist Perdurantism'. Sats - Nordic Journal of Philosophy 8, 7988. 
- (2008) 'The bundle theory and the substratum theory: deadly enemies or twin brothers?'. Philosophical Studies 141, 175-190.

Bickhard, M. (2008) 'Issues in process metaphysics'. Ecological Psychology 20, 252-256.

Bottani, A.C. (2016) 'Bringing back intrinsics to enduring things'. Synthese (online first), doi: 10.1007/s11229-016-1157-2.

Brogaard, B. (2000) 'Presentist Four-Dimensionalism'. The Monist 83, 341-356.

Chisholm (1969) 'The Loose and Popular and the Strict and Philosophical Senses of Identity'. In N. Care/H. Grimm (eds.), Perception and Identity. Cleveland: Case Western Reserve University Press, 82-106.

Dupré, J.A. (2012) Processes of Life. Essays in the Philosophy of Biology. Oxford: Oxford University Press.

Gallois, A. (2015) 'Identity Over Time', The Stanford Encyclopedia of Philosophy (Winter 2015 Edition), Edward N. Zalta (ed.), URL = <http://plato.stanford.edu/archives/ win2015/entries/identity-time/>.

Galton, A. (2017) 'The Dynamic Present'. In P. Hasle/P. Blackburn/P. Øhrstrøm (eds.), Logic and Philosophy of Time: Themes from Prior. Aalborg: Aalborg University Press, 167-186.

Galton, A./Mizoguchi, R. (2009) 'The water falls but the waterfall does not fall: New perspectives on objects, processes and events'. Applied Ontology 4, 71-107.

Geach, P.T. (1972) Logic Matters. Oxford: Blackwell.

- (1979) Truth, Love and Immortality: An Introduction to McTaggart's Philosophy. London: Hutchinson.

Hansen, J. (2010) 'A Case for Stage View Presentism'. Logos: Cornell University's Undergraduate Philosophy Journal, URL = <https://philpapers.org/archive/HANACF.pdf >

Haslanger, S. (1989a) 'Endurance and Temporary Intrinsics'. Analysis 49, 119-125.

- (1989b) 'Persistence, Change, and Explanation', Philosophical Studies 56, 1-28.

- (2003) 'Persistence through Time'. In M.J. Loux/D.W. Zimmerman (eds.), The Oxford Handbook of Metaphysics. Oxford: Oxford University Press, 315-354. 
Hinchcliff, M. (1996) 'The Puzzle of Change'. In J.E. Tomberlin (ed.), Philosophical Perspectives X: Metaphysics (Atascadero, California: Ridgeview), 19-36.

Johnston, M. (1987) 'Is there a problem about persistence?'. Proceedings of the Aristotelian Society $61,107-135$.

Lewis, D.K. (1986) On the Plurality of Worlds. Oxford: Blackwell.

- (1988) 'Rearrangement of Particles: Reply to Lowe'. Analysis 48, 65-72.

- (1991) Parts of Classes. Oxford: Blackwell.

- (2002) 'Tensing the Copula'. Mind 111, 1-14.

Lowe, E.J. (1988) 'The Problem of Intrinsic Change. Rejoinder to Lewis'. Analysis 48, 72-77.

McTaggart, J.M.E. (1927) The Nature of Existence, Vol. 2. Cambridge: Cambridge University Press.

Meincke, A.S. (2015) Auf dem Kampfplatz der Metaphysik. Kritische Studien zur transtemporalen Identität von Personen. Münster: Mentis.

- (2018a) 'Persons as Biological Processes. A Bio-Processual Way-Out of the Personal Identity Dilemma'. In D.J. Nicholson/J.A. Dupré (eds.), Everything Flows. Towards a Processual Philosophy of Biology. Oxford: Oxford University Press, 357-378.

- (2018b) 'Autopoiesis, Biological Autonomy and the Process View of Life'. European Journal for Philosophy of Science 9:5, URL = <https://doi.org/10.1007/s13194-0180228-2>.

- (forthcoming) 'Human Persons - A Process View'. In J. Noller (ed.), Was sind und wie existieren Personen? Münster: Mentis, 53-76.

Merricks, T. (1994) 'Endurance and Indiscernibility'. Journal of Philosophy 91, 165-184.

Nicholson, D.J./Dupré, J.A. (eds.), Everything Flows. Towards a Processual Philosophy of Biology. Oxford: Oxford University Press.

Oderberg, D.S. (2004) 'Temporal Parts and the Possibility of Change'. Philosophy and Phenomenological Research 69, 686-708.

Seibt, J. (1997) 'Existence in Time: From Substance to Process'. In: J. Faye et al. (eds.), Perspectives on Time, Dordrecht: Kluwer, 143-182. 
Sider, T. (2001) Four-Dimensionalism: An Ontology of Persistence and Time. Oxford: Oxford University Press.

Simons, P. (2000a) Parts: A Study in Ontology. Oxford: Oxford University Press.

- (2000b) 'Continuants and Occurrents'. Aristotelian Society Supplementary Volume 74, 59-75.

Steward, H. (2013) 'Processes, Continuants, and Individuals'. Mind 122, 781-812.

- (2015) 'What is a Continuant?' Proceedings of the Aristotelian Society Supplementary Volume 89, 109-123.

Stout, R. (1997) 'Processes'. Philosophy 72, 119-127.

- (2016) 'The Category of Occurrent Continuants'. Mind 125, 41-62.

Tooley, M. (1997). Time, Tense, and Causation. Oxford: Clarendon Press.

Van Inwagen, P. (1990) 'Four-dimensional Objects'. Noûs 24, 245-255.

Wasserman, R. (2003) 'The Argument from Temporary Intrinsics'. Australasian Journal of Philosophy 81, 413-419.

- (2006) 'The Problem of Change'. Philosophy Compass 1, 48-57. 